\title{
Article \\ Effect of the Anionic Counterpart: Molybdate vs. Tungstate in Energy Storage for Pseudo-Capacitor Applications
}

\author{
Pratigya Sharma ${ }^{1} \mathbb{D}$, Manickam Minakshi ${ }^{1, * \mathbb{D}}$, Jonathan Whale ${ }^{1}$, Annelise Jean-Fulcrand ${ }^{2,3}$ \\ and Georg Garnweitner $2,3, *$ (D) \\ 1 Engineering and Energy, Murdoch University, Perth, WA 6150, Australia; \\ Pratigya.Sharma@murdoch.edu.au (P.S.); j.whale@murdoch.edu.au (J.W.) \\ 2 Institut für Partikeltechnik, Technische Universität Braunschweig, Volkmaroder Straße 5, \\ 38104 Braunschweig, Germany; a.jean-fulcrand@tu-braunschweig.de \\ 3 Laboratory for Emerging Nanometrology, Technische Universität Braunschweig, Langer Kamp 6A, \\ 38106 Braunschweig, Germany \\ * Correspondence: minakshi@murdoch.edu.au (M.M.); g.garnweitner@tu-braunschweig.de (G.G.)
}

Citation: Sharma, P.; Minakshi, M.; Whale, J.; Jean-Fulcrand, A.;

Garnweitner, G. Effect of the Anionic Counterpart: Molybdate vs.

Tungstate in Energy Storage for

Pseudo-Capacitor Applications.

Nanomaterials 2021, 11, 580. https://

doi.org/10.3390/nano11030580

Academic Editor: Yanbing He

Received: 22 January 2021

Accepted: 22 February 2021

Published: 26 February 2021

Publisher's Note: MDPI stays neutral with regard to jurisdictional claims in published maps and institutional affiliations.

Copyright: (c) 2021 by the authors. Licensee MDPI, Basel, Switzerland. This article is an open access article distributed under the terms and conditions of the Creative Commons Attribution (CC BY) license (https:// creativecommons.org/licenses/by/ $4.0 /)$.

\begin{abstract}
Nickel-based bimetallic oxides (BMOs) have shown significant potential in battery-type electrodes for pseudo-capacitors given their ability to facilitate redox reactions. In this work, two bimetallic oxides, $\mathrm{NiMoO}_{4}$ and $\mathrm{NiWO}_{4}$, were synthesized using a wet chemical route. The structure and electrochemical properties of the pseudo-capacitor cathode materials were characterized. $\mathrm{NiMoO}_{4}$ showed superior charge storage performance in comparison to $\mathrm{NiWO}_{4}$, exhibiting a discharge capacitance of 124 and $77 \mathrm{~F} \cdot \mathrm{g}^{-1}$, respectively. $\mathrm{NiMoO}_{4}$, moreover, demonstrates better capacity retention after 1000 cycles with $87.14 \%$ compared to $82.22 \%$ for $\mathrm{NiWO}_{4}$. The lower electrochemical performance of the latter was identified to result from the redox behavior during cycling. $\mathrm{NiWO}_{4}$ reacts in the alkaline solution and forms a passivation layer composed of $\mathrm{WO}_{3}$ on the electrode, while in contrast, the redox behavior of $\mathrm{NiMoO}_{4}$ is fully reversible.
\end{abstract}

Keywords: energy storage; electrode materials; asymmetric pseudo-capacitor

\section{Introduction}

The successful transition to fully sustainable energy systems cannot be achieved without improving the management and storage of energy. Thereby, the development of a wide range of energy storage devices is key in order to satisfy all type of applications. In recent years, research studies on energy storage systems, such as fuel cells, batteries, pseudocapacitors, and supercapacitors have been extremely active, especially for applications such as transportation and renewable energy [1].

Unlike batteries, supercapacitors possess high power density but exhibit low energy density, limiting their use. Pseudo-capacitors were developed to fill the gap between batteries and supercapacitors. They achieve a better energy density compared to supercapacitors by storing charge chemically through redox reactions. In order to improve the energy density while maintaining excellent power density and cycle stability properties, various electro-active materials are being investigated, which are able to store the energy via quick redox reactions occurring at the interface between the electrode and electrolyte. In particular, transition metal oxides such as $\mathrm{RuO}_{2}, \mathrm{MnO}_{2}, \mathrm{NiO}$, and $\mathrm{CoO}$ are widely investigated as cathode materials for such pseudo-capacitors [2,3]. However, metal oxides possess a high electrical resistance and usually need to be combined with conductive electroactive materials like activated carbon, carbon fibers (CF), and carbon nanotubes (CNT) [4]. By doping a single metal oxide with other transition metals, a novel material with multiple oxidation states can be obtained, inducing redox reactions, in analogy to a battery electrode, and reducing the charge transfer resistance [5]. In this context, nickel-based bimetallic oxides (BMOs) are excellent candidates for battery-type electrodes for pseudo-capacitors. Several 
Ni-BMOs were developed, such as $\mathrm{NiMoO}_{4}$ [6], $\mathrm{NiCo}_{2} \mathrm{O}_{4}$ [5], and $\mathrm{NiMnO}$ [7]. A range of BMOs were previously synthesized via various routes including sol-gel synthesis $[8,9]$, ball milling [10], and hydrothermal strategies [6,9], which resulted in highly diverse nanostructures, such as mesoporous materials [11,12], nanosheets [5], and nanowires [6]. The formation of nanostructured BMOs is an effective way to increase the specific surface area and to obtain a higher specific capacitance. More metal centers are accessible to promote redox reactions and to facilitate electron and ion exchange at the interface [2], hereby, improving the capacitative performance.

$\mathrm{NiMoO}_{4}$ was previously investigated for pseudo-capacitor applications because of its high electrochemical energy storage density, which originates from the high capacitance of $\mathrm{NiO}$ (theoretical capacitance $(\sim 2500 \mathrm{~F} / \mathrm{g})$ and the enhanced conductivity due to $\left.\mathrm{MoO}_{3}\right)$. $\mathrm{NiMoO}_{4}$ can be synthesized in the $\alpha$-phase and the $\beta$-phase [6], and it was observed that $\beta-\mathrm{NiMoO}_{4}$ possesses a higher electrical conductivity than $\alpha-\mathrm{NiMoO}_{4}[13]$.

In contrast, $\mathrm{NiWO}_{4}$ has been investigated predominantly as a catalyst for wastewater treatment [11]. However, its excellent electrical conductivity $\left(\sim 10^{-7}\right.$ to $\left.10^{-3} \mathrm{~S} \cdot \mathrm{cm}^{-1}\right)$ compared to $\mathrm{NiO}\left(10^{-13} \mathrm{~S} \cdot \mathrm{cm}^{-1}\right)$ can be beneficial for energy storage systems [14]. At the present time, $\mathrm{NiWO}_{4}$ has barely been studied for pseudo-capacitor applications [14,15]. $\mathrm{Niu}$ [14] observed that $\mathrm{NiWO}_{4}$ exhibits higher capacitance when in its amorphous form.

The use of engineered materials with a controlled structure and crystal properties is crucial for the improvement of energy storage systems [16]. In this study, the influence of the anion counterpart (molybdate vs. tungstate) of the synthesized Ni-based BMOs is studied in detail. $\mathrm{NiMoO}_{4}$ and $\mathrm{NiWO}_{4}$ nanostructures are synthesized using a single step low-temperature hydrothermal process. The crystal structure and morphology of the obtained products are investigated using X-ray diffraction (XRD) and electron microscopy (SEM and TEM). The molecular structure of the material is characterized with Raman and infrared spectroscopy as well as energy-dispersive X-ray spectroscopy (EDX). The influence of the type of anion on the structure is then compared to the electrochemical performance. The synthesized Ni-based BMOs have been electrochemically activated by cyclic voltammetry and tested as the electrode for a pseudo-capacitor. The nickel-based BMOs are cycled against an activated carbon anode to obtain an asymmetric pseudocapacitor. Finally, the electrochemical properties of both Ni-based BMOs are investigated using cyclic voltammetry and the constant current-constant voltage $(\mathrm{CC} / \mathrm{CV})$ charge method. The obtained electrochemical properties are compared and related to chemical and structural differences between the two materials.

\section{Materials and Methods}

\subsection{Synthesis of Nickel Molybdate and Nickel Tungstate}

All the chemicals used were of an analytical grade, obtained from Sigma Aldrich, New South Wales, Australia, and used without further purification. A facile hydrothermal approach was adopted as a route for synthesizing $\mathrm{NiMoO}_{4}$ and $\mathrm{NiWO}_{4}$ nanoparticles [9]. In a typical synthesis, for nickel molybdate $\left(\mathrm{NiMoO}_{4}\right), 1 \mathrm{mmol}$ of nickel nitrate $\left(\mathrm{Ni}\left(\mathrm{NO}_{3}\right)_{2} \cdot 6 \mathrm{H}_{2} \mathrm{O}\right)$ and $1 \mathrm{mmol}$ of sodium molybdate $\left(\mathrm{Na}_{2} \mathrm{MoO}_{4} \cdot 2 \mathrm{H}_{2} \mathrm{O}\right)$ were dissolved in deionized water under sonication conditions. The homogenous solution was then transferred to a 50-mL Teflon-lined stainless-steel autoclave, which was sealed and heated to $140{ }^{\circ} \mathrm{C}$ for $12 \mathrm{~h}$ to carry out the reaction. The product was then washed with a copious amount of ethanol and deionized water and, finally, dried overnight in an oven maintained at $60^{\circ} \mathrm{C}$. The final product termed as " $\mathrm{NiMoO}_{4}$ " was then subjected to various physical and electrochemical characterizations in this study and the entire process is illustrated in Figure 1. Likewise, nickel tungstate $\left(\mathrm{NiWO}_{4}\right)$ was synthesized under identical conditions except $1 \mathrm{mmol}$ of sodium tungstate $\left(\mathrm{Na}_{2} \mathrm{WO}_{4} \cdot 2 \mathrm{H}_{2} \mathrm{O}\right)$ was used instead of sodium molybdate. The hydrothermal synthesis of tungsten oxide $\left(\mathrm{WO}_{3}\right)$ is described in the supplementary information section (Figure S1). 


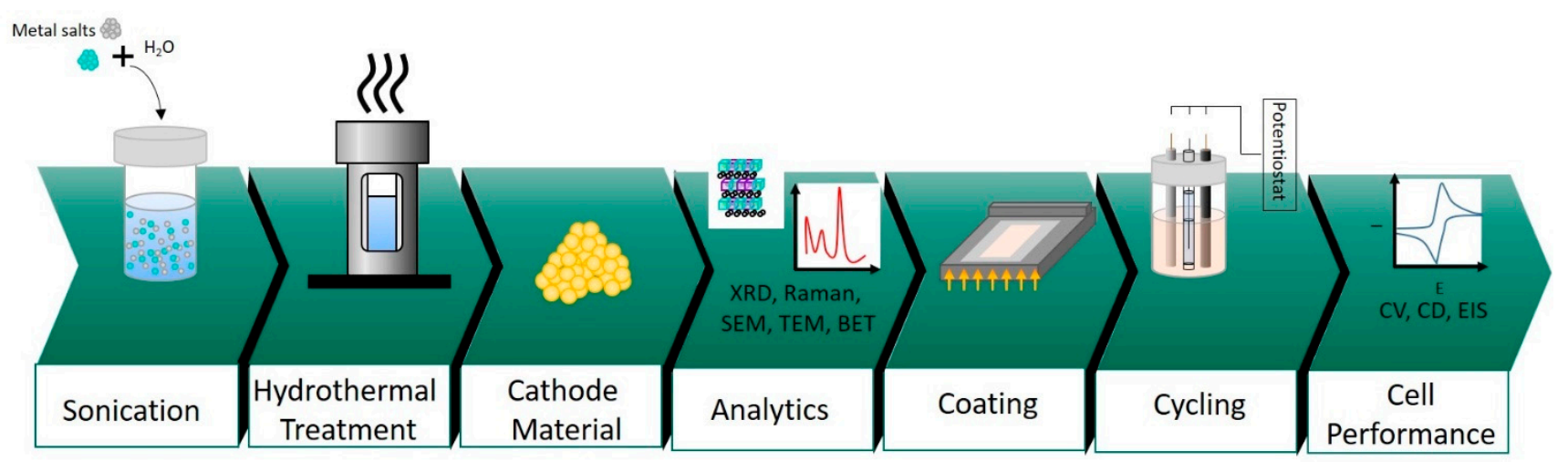

Figure 1. Schematic illustration of the various process steps from synthesis to characterization.

\subsection{Physical Characterization of $\mathrm{NiMoO}_{4}$ and $\mathrm{NiWO}_{4}$}

Raman spectra (Alpha300 R-Confocal Raman Imaging, with a $532 \mathrm{~nm}$ Nd:YAG laser, WITec, Ulm, Germany) were recorded to provide information on the chemical composition. The crystallinity and phase identification of the as-prepared powder samples was carried out using X-ray diffraction (XRD) with a $\mathrm{Cu} \mathrm{K} \alpha$ radiation (Empyrean $\mathrm{Cu}$ LEF HR goniometer, Almelo, Netherlands) on a Si sample holder, operating at $40 \mathrm{kV}$ and $30 \mathrm{~mA}$ over the $2 \theta$ range of $10^{\circ}-70^{\circ}$ (Empyrean series 2, PANalytical PIXcel-3D detector, Almelo, Netherlands).X-ray photoelectron spectra (XPS) were obtained using a Kratos AXIS Nova instrument (Kratos Analytical, Manchester, UK) with the aid of monochromatic Al- $\kappa_{\alpha}$ radiation operating at $15 \mathrm{kV}$ and $10 \mathrm{~mA}$. A pressure of $<1 \times 10^{-7} \mathrm{~Pa}$ was maintained and the $\mathrm{C} 1$ s peak was corrected at $284.8 \mathrm{eV}$ prior to analysis. The particle size distribution of the two synthesized materials was measured by a LUMiSizer device from LUM GmbH, Berlin, Germany. The samples were first dispersed in N-methyl-2-pyrrolidone (NMP) at a $5 \mathrm{wt} . \%$ concentration. Then the particles in suspension were sedimented at three different speeds ( $300 \mathrm{rpm}$ for $300 \mathrm{~s}, 2000 \mathrm{rpm}$ for $200 \mathrm{~s}$, and $4000 \mathrm{rpm}$ for $200 \mathrm{~s}$ ). The structural and composition properties of the samples were studied using scanning electron microscopy (SEM) with a secondary electron (SE) detector (Helios G4 CX Dual-Beam, Thermo Fisher Scientific, MA, USA) as well as transmission electron microscopy (TEM) (Tecnai G2 F20, FEI, USA). The surface area was evaluated by nitrogen sorption with the Brunauer-Emmett-Teller (BET) method (NOVA 2000e, Quantachrome, Odelzhausen, Germany).

\subsection{Electrochemical Analysis}

To investigate the differences in the electrochemical properties between molybdate and tungstate, electrochemical measurements were carried out in $2 \mathrm{M} \mathrm{NaOH}$ solution using a BioLogic SP-150 workstation (BioLogic Science Instrument, Seyssinet-Pariset, France). For three-electrode configurations, either the molybdate or tungstate sample, served as a working electrode. A platinum wire $(1 \mathrm{~mm}$ in diameter and $10 \mathrm{~cm}$ in length) was used as a counter electrode, and mercury-mercuric oxide $(\mathrm{Hg} / \mathrm{HgO})$ served as a reference electrode. The working electrodes were composed of $\mathrm{NiMoO}_{4}$ or $\mathrm{NiWO}_{4}$, carbon black, and polyvinylidene fluoride $(\mathrm{PVdF})$ in the weight ratio of 75:15:10, respectively. The materials were dispersed in $400 \mu \mathrm{L}$ of N-methyl-2-pyrrolidone (NMP) and mixed in an agate mortar, producing a slurry. The homogenous mixture (approximately $7 \mathrm{mg}$ for both $\mathrm{NiMoO}_{4}$ and $\mathrm{NiWO}_{4}$ ) was then coated (as shown in Figure 1) on a graphite sheet as a current collector (having an area of $1 \mathrm{~cm}^{2}$ ), and was subsequently dried in an oven at $80^{\circ} \mathrm{C}$ for $5 \mathrm{~h}$. Cyclic voltammetry $(\mathrm{CV})$ and charge-discharge experiments were measured in a potential window of 0 to $0.6 \mathrm{~V}$.

For a two-electrode configuration, the synthesized materials $\left(\mathrm{NiMoO}_{4}\right.$ or $\left.\mathrm{NiWO}_{4}\right)$ were used as a positive electrode, and activated carbon (AC) as the negative electrode. To test the suitability of the cathode material for asymmetric pseudo-capacitor applications, the measurements were carried out within the potential range of 0-1.6 V. Electrochemical impedance 
spectroscopy (EIS) was performed in a frequency range from 0.01 to $100,000 \mathrm{~Hz}$ using an open circuit potential. The specific capacitance $\left(C_{S}\right)$, energy density $(E)$, and power density $(P)$ of the asymmetric pseudo-capacitor were calculated using the following relations.

$$
\begin{gathered}
C_{s}=\frac{i \Delta t}{m \Delta V} \\
E=\frac{1}{2} C_{s} V^{2} \\
P=3600 E / \Delta t
\end{gathered}
$$

where $i$ is the constant discharge current (A), $\Delta t$ is the discharge time (s), $\mathrm{m}$ is the mass of active material $(\mathrm{g})$, and $\Delta V$ is the potential window $(V)$.

The mass ratio of the positive and negative electrodes was balanced using the equation below for an asymmetric device, to aid in sustaining the charge conservation between two electrodes.

$$
\frac{m^{+}}{m^{-}}=\frac{C_{s-} \times \Delta V_{-}}{C_{s+} \times \Delta V_{+}}
$$

In the above equations, $m$ represents the mass of active material in $g . C_{s_{-}}, C_{s_{+}}$, and $\Delta V_{-}, \Delta V_{+}$represent the specific capacitance and potential window of the negative and the positive electrode, respectively. For a three-electrode configuration, the specific capacitance of $\mathrm{NiMoO}_{4}$ and $\mathrm{NiWO}_{4}$ was calculated to be $392.53 \mathrm{~F} \cdot \mathrm{g}^{-1}$ and $246.25 \mathrm{~F} \cdot \mathrm{g}^{-1}$, respectively. Using Equation (4), an optimized mass ratio between anode and cathode material was determined. The mass ratio between $\mathrm{NiMoO}_{4}$ and activated carbon (AC) was calculated to be 0.917 , whereas that of $\mathrm{NiWO}_{4}$ and $\mathrm{AC}$ was 1.461 . For $15 \mathrm{mg}$ of $\mathrm{NiMoO}_{4}, 13.75 \mathrm{mg}$ of $\mathrm{AC}$ was taken whereas, for $15 \mathrm{mg}$ of $\mathrm{NiWO}_{4}, 21.91 \mathrm{mg}$ of $\mathrm{AC}$ was taken and, hence, the asymmetric capacitor was constructed.

\section{Results and Discussion}

\subsection{Chemical and Structural Characterization of $\mathrm{NiMoO}_{4}$ and $\mathrm{NiWO}_{4}$}

Figure 2A,B show the powder X-ray powder diffraction (XRD) patterns of the synthesized products. It was observed that, at given identical synthesis conditions, the pattern of the $\mathrm{NiMoO}_{4}$ sample (Figure 2A) shows sharp reflections and, hence, is highly crystalline. The main reflections observed in the given $2 \theta$ range are at the values of $14.29,21.73,23.96$, $28.82,36.41$, and $50.64^{\circ}$ and can be correlated with the (110), (-211), (-121), (220), (-231), and (-341) reflections of the monoclinic $\alpha$-phase of $\mathrm{NiMoO}_{4}$ (standard JCPDS card no. 00033-0948), with lattice parameters $\mathrm{a}=9.50 \AA, \mathrm{b}=8.75 \AA$, and $\mathrm{c}=7.66 \AA, \beta=113.13^{\circ}$ and $\mathrm{a}$ space group of $\mathrm{I} 2 / \mathrm{m}[6]$. In addition, further reflections at $2 \theta$ positions of $27.19,33.69,41.74$, $43.87,45.57,47.59,53.58,54.59,56.13$, and $61.74^{\circ}$ were assigned to the (11-2), (31-2), (222), (33-2), (51-1), (51-2), (44-1), (242), (44-2), and (06-1) planes, respectively, corresponding to the $\beta$-phase of $\mathrm{NiMoO}_{4}$ (standard JCPDS card no. 00-045-0142). The lattice parameters for this $\beta$-phase are $\mathrm{a}=10.18 \AA, \mathrm{b}=9.24 \AA, \mathrm{c}=7.02 \AA$, and $\beta=107.09^{\circ}$ with a space group of $\mathrm{C} 2 / \mathrm{m}[6]$. Hence, the presence of both the $\alpha$-form and the $\beta$-form of $\mathrm{NiMoO}_{4}$ is observed in the XRD analysis, while the $\alpha$-phase is the predominant one. On the other hand, in Figure $2 \mathrm{~B}$, much broader reflections are observed for the product of the nickel tungstate synthesis, indicating small crystallite sizes and lower crystallinity. The individual signals at $23.96,30.92,36.57,41.66,54.62$, and $63.70^{\circ} 2 \theta$ correlate well with the (011), (-111), (002), (-102), (-202), and (230) reflections of wolframite-type $\mathrm{NiWO}_{4}$ (standard JCPDS card no. 00-015-755) with the lattice parameters $\mathrm{a}=4.60 \AA, \mathrm{b}=5.66 \AA$, and $\mathrm{c}=4.91 \AA, \beta=90.01^{\circ}$, and a space group of $\mathrm{P} 2 / \mathrm{c}$. The standard monoclinic structure of $\alpha-\mathrm{NiMoO}_{4}$ and $\mathrm{NiWO}_{4}$ is illustrated in Figure 3. In the $\alpha-\mathrm{NiMoO}_{4}$ crystal structure (Figure 3A), the Mo sites possess a six-fold coordination geometry with $\mathrm{O}$ atoms. In the case of $\beta-\mathrm{NiMoO}_{4}$ (not shown), two types of Mo-O coordination can be observed, which are (a) Mo-O possessing an octahedral coordination, similar to the one observed for $\alpha-\mathrm{NiMoO}_{4}$, and (b) a tetrahedral coordination with Mo atoms at the centers forming irregular tetrahedra. The Ni atom is coordinated with 
six $\mathrm{O}$ atoms forming edge-sharing $\mathrm{NiO}_{6}$ octahedra in both the $\alpha$-phase and the $\beta$-phase. On the other hand, $\mathrm{NiWO}_{4}$ (Figure $3 \mathrm{~B}$ ) features $\mathrm{W}$ sites coordinated to six $\mathrm{O}$ atoms forming distorted $\mathrm{WO}_{6}$ octahedra, which share corners with eight surrounding $\mathrm{NiO}_{6}$ octahedra and edges with two neighboring $\mathrm{WO}_{6}$ octahedra.
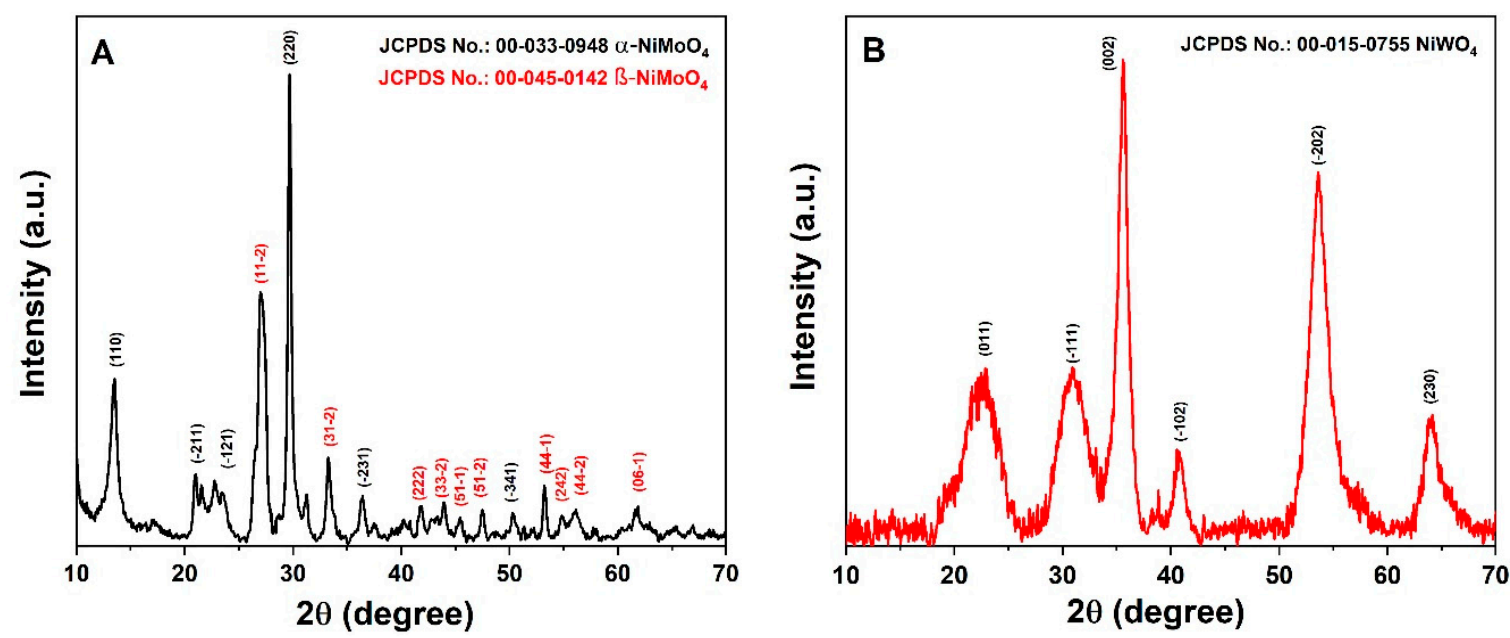

Figure 2. X-ray diffraction patterns of hydrothermally synthesized (A) $\alpha$ - and $\beta-\mathrm{NiMoO}_{4}$, and (B) $\mathrm{NiWO}_{4}$ as indicated in the figure.
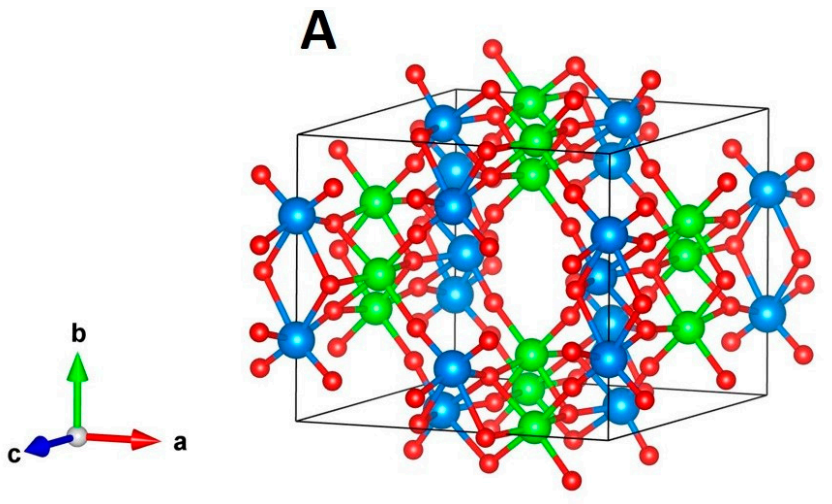

ONi
Mo $\odot 0$
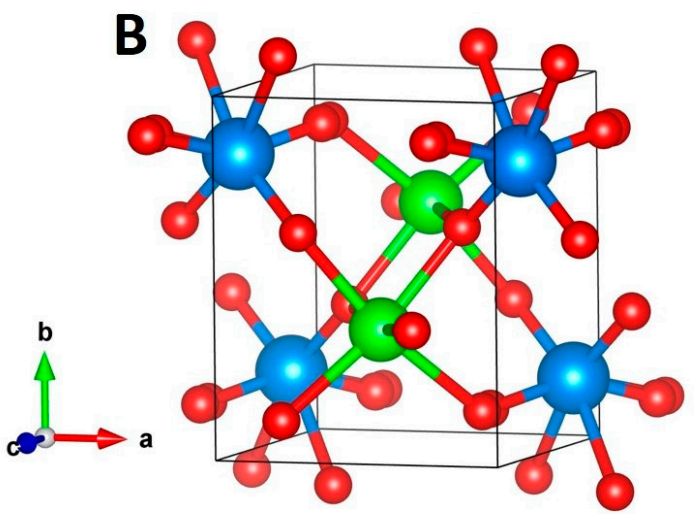

ONi

Figure 3. Crystal structure of monoclinic (A) $\alpha-\mathrm{NiMoO}_{4}$ and (B) $\mathrm{NiWO}_{4}$ illustrating the coordination relationship of $\mathrm{NiO}_{6}$ with $\mathrm{MoO}_{6}$ octahedra and distorted $\mathrm{WO}_{6}$ in $\mathrm{NiMoO}_{4}$ and $\mathrm{NiWO}_{4}$, respectively.

The chemical structure of the synthesized $\mathrm{NiMoO}_{4}$ and $\mathrm{NiWO}_{4}$ is characterized with Raman spectroscopy and is shown in Figure 4. The Raman spectrum for $\alpha, \beta-$ $\mathrm{NiMoO}_{4}$ exhibits a combination of Mo-O vibrations that are characteristics of the tetrahedral structure of the $\mathrm{MoO}_{4}$ anion [17-19] at 949,880 and $816 \mathrm{~cm}^{-1}$, and of peaks typical for Mo-O bonds in an octahedral coordination at 940 and $872 \mathrm{~cm}^{-1}$. Thereby, the bands at 949 and $940 \mathrm{~cm}^{-1}$ are assigned to the symmetric stretching mode of the Mo-O bond, whereas the bands observed at 880,872 , and $816 \mathrm{~cm}^{-1}$ are assigned to the asymmetric stretching in the OMo-O chain. The bands at 372 and $359 \mathrm{~cm}^{-1}$ are attributed to the asymmetric and symmetric bending modes of O-Mo-O, and the band at $762 \mathrm{~cm}^{-1}$ is associated with the symmetric stretching vibration of Ni-O-Mo [19-22]. Ross et al. [23,24] previously investigated the effect of doping metal tungstates $\mathrm{MWO}_{4}$ with cations of different sizes. In their studies, it was observed that the use of small metal cations (with an ionic radius $<0.77 \AA$ ) like Ni favors the formation of a distorted $\mathrm{WO}_{6}$ structure [23]. Doudin [25] researched further the structure 
of $\mathrm{NiWO}_{4}$, and noticed that it consists of $\left[\mathrm{NiO}_{6}\right]$ and $\left[\mathrm{WO}_{6}\right]$ octahedra. The octahedra are connected differently, depending on the central atom. Octahedra with the same central atom are edge-connected, whereas the octahedra with different central atoms are cornerconnected $[22,26]$. The Ni-O bonds have similar lengths while $\mathrm{W}-\mathrm{O}$ bonds are asymmetrical, leading to a distorted structure. Consequently, the Raman activity is dominated by the tungsten sub-lattice. The band at $899 \mathrm{~cm}^{-1}$ is assigned with the symmetric $\mathrm{W}=\mathrm{O}$ stretching of the $\mathrm{WO}_{6}$ lattice and is in agreement with previous results [23]. The mode at $373 \mathrm{~cm}^{-1}$ is assigned to the symmetric vibration of $\mathrm{NiO}_{6}$ octahedra [27]. The bands at 809 and $690 \mathrm{~cm}^{-1}$ correspond to the bridging W-O-W stretching and the signal at $215 \mathrm{~cm}^{-1}$ to the bending $\mathrm{W}-\mathrm{O}-\mathrm{W}$ mode $[23,26,28]$. It should be pointed out that the band located at $\sim 951 \mathrm{~cm}^{-1}$ is observed when measuring microcrystalline tungstate nanoparticles [29]. The Raman and XRD results of the synthesized materials corroborate the presence of two phases $(\alpha, \beta)$ for $\mathrm{NiMoO}_{4}$ and of a single phase for $\mathrm{NiWO}_{4}$.

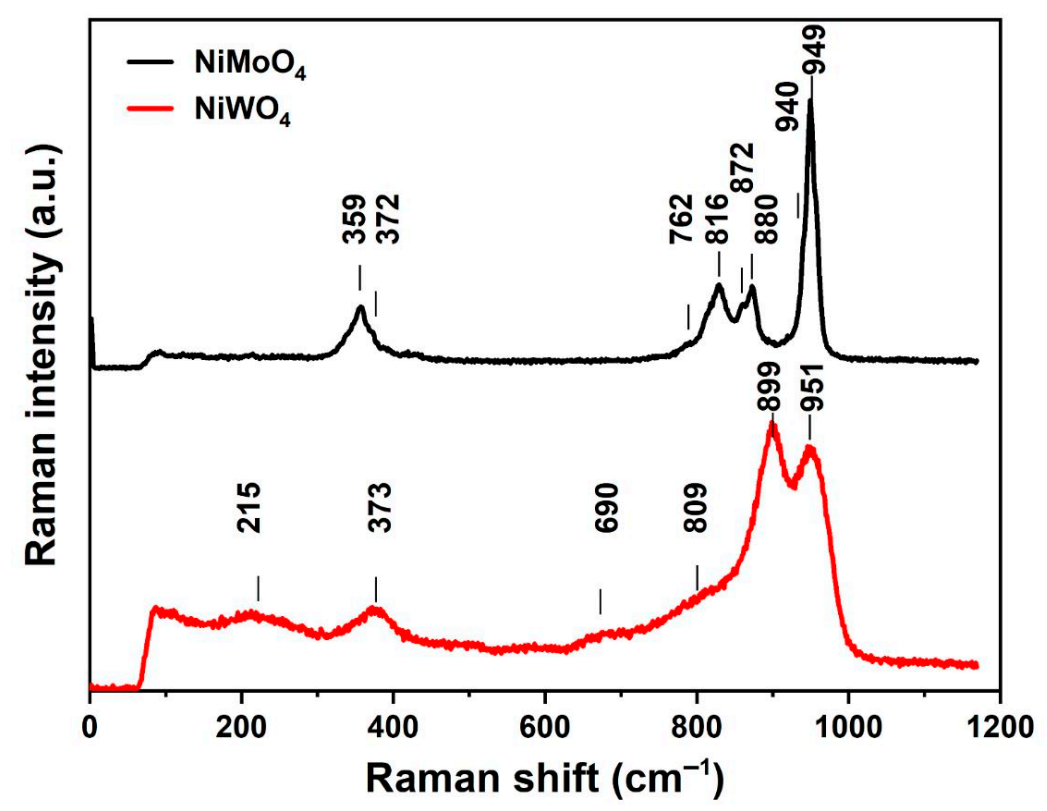

Figure 4. Raman spectra of hydrothermally synthesized $\mathrm{NiMoO}_{4}$ and $\mathrm{NiWO}_{4}$.

The chemical oxidation state of the elements in both $\mathrm{NiMoO}_{4}$ and $\mathrm{NiWO}_{4}$ were studied by X-ray photoelectron spectroscopy. The obtained spectra of each element in the as-synthesized materials are shown in Figure 5. Survey spectra of both are provided in the $\mathrm{S} 1$ section (Figure S2). As expected, the survey spectra show the presence of Ni 2p, Mo 3d, W 4f, and $\mathrm{O} 1 \mathrm{~s}$ peaks in the samples. Based on the Gaussian fitting model, two major peaks with binding energy values of 853.04 and $870.91 \mathrm{eV}$ could be derived for $\mathrm{Ni} 2 \mathrm{p}$, which can be assigned to $\mathrm{Ni} 2 \mathrm{p}_{3 / 2}$ and $\mathrm{Ni} 2 \mathrm{p}_{1 / 2}$. The energy separation of $\mathrm{Ni} 2 \mathrm{p}_{3 / 2}-\mathrm{Ni} 2 \mathrm{p}_{1 / 2}$ is about $17.87 \mathrm{eV}$, which indicates the presence of $\mathrm{Ni}^{2+}$. In addition, two satellite peaks at binding energies of 859.81 and $877.50 \mathrm{eV}$ could be observed. This was observed for both $\mathrm{NiMoO}_{4}$ and $\mathrm{NiWO}_{4}$ samples, as shown in Figure 5A,B. Two major peaks at binding energy values of 228.93 and $232.05 \mathrm{eV}$ for the Mo $3 \mathrm{~d}$ spectrum were observed in the $\mathrm{NiMoO}_{4}$ sample (Figure $5 \mathrm{C}$ ), relating to Mo $3 \mathrm{~d}_{5 / 2}$ and Mo $3 \mathrm{~d}_{3 / 2}$ levels, respectively. This spin-orbit splitting value is $3.12 \mathrm{eV}$, denoting the presence of $\mathrm{Mo}^{6+}$ [30]. Furthermore, the high resolution XPS spectrum of $\mathrm{W} 4 \mathrm{f}$ (Figure 5D) shows two major peaks with binding energies of $32.8 \mathrm{eV}$ and $34.9 \mathrm{eV}$ corresponding to $\mathrm{W} 4 \mathrm{f}_{7 / 2}$ and $\mathrm{W} 4 \mathrm{f}_{5 / 2}$ levels, respectively, inferring the presence of $\mathrm{W}$ in the +6 state. The spin energy separation of $2.1 \mathrm{eV}$ is consistent with the previously reported values [31]. The typical metal oxygen metal (M-O-M) bond is observed at binding energies of 526.84 and $528.59 \mathrm{eV}$ in the $\mathrm{O}$ 1s spectra for both $\mathrm{NiMoO}_{4}$ and $\mathrm{NiWO}_{4}$ samples (Figure 5E,F). These results confirm the formation of $\mathrm{NiMoO}_{4}$ and $\mathrm{NiWO}_{4}$. 

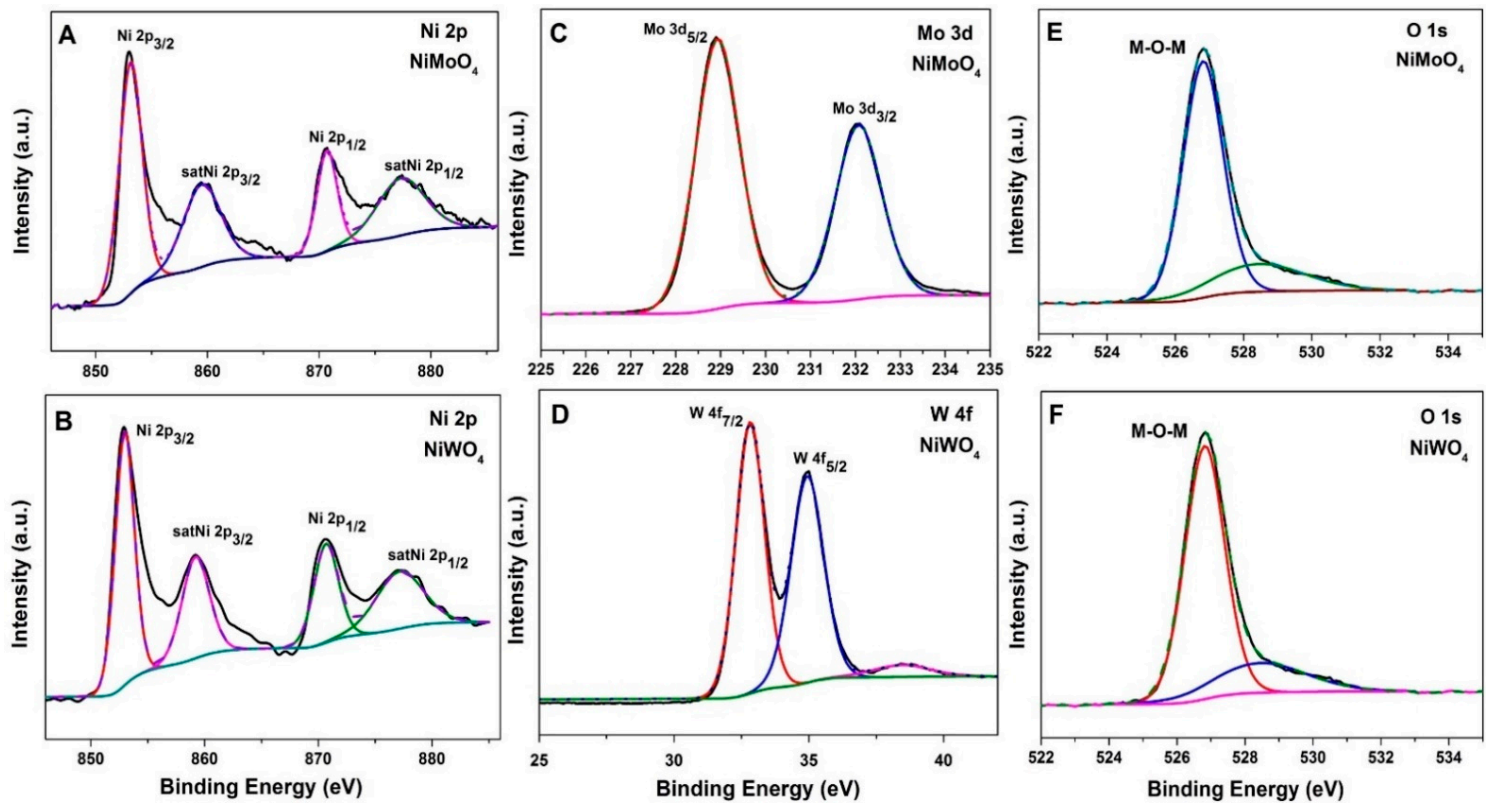

Figure 5. X-ray photoelectron spectra of (A,B) Ni 2p, (C) Mo 3d, (D) W 4f and (E,F) O 1s core level regions of hydrothermally synthesized $\mathrm{NiMoO}_{4}$ and $\mathrm{NiWO}_{4}$.

The surface topography and the particle size of the products were determined using SEM (Figure 6) and TEM images (Figure 7). The SEM images of the $\mathrm{NiMoO}_{4}$ sample (Figure 6A-C) show that the material consists of nanorods that are nested together into spherical agglomerates. The average hydrodynamic particle size of the agglomerates as present in N-methyl-2-pyrrolidone (NMP) dispersion is measured to be $\mathrm{X}_{\mathrm{v}, 10}=5.2 \mu \mathrm{m}$, $X_{v, 50}=6 \mu \mathrm{m}$, and $X_{v, 90}=7.6 \mu \mathrm{m}$ using sedimentation analysis (Figure 8). The individual nanorods are clearly visible in the magnified TEM images in Figure 7A-C, showing a diameter of $\sim 40-200 \mathrm{~nm}$ and a length in the range of $\sim 500 \mathrm{~nm}$ to $2 \mu \mathrm{m}$. The morphology of the $\mathrm{NiWO}_{4}$ particles was significantly different, with the SEM images (Figure 6D-F) showing flake-like structures with a rough surface. The average hydrodynamic size of these structures as present in NMP dispersion amounts to $X_{\mathrm{v}, 10}=3.8 \mu \mathrm{m}, X_{\mathrm{v}, 50}=8.6 \mu \mathrm{m}$, and $X_{v, 90}=12.4 \mu \mathrm{m}$, which is somewhat larger than for the $\mathrm{NiMoO}_{4}$ sample. Figure 7D-F show that the material is composed of smaller clusters of nanoparticles. The primary nanocrystals are in the $5 \mathrm{~nm}$-range, which explains the strong signal broadening in the XRD pattern. The morphological and structural variations between the two bimetallic oxides (BMO) samples have a strong impact on their respective, specific, surface area. For the $\mathrm{NiWO}_{4}$ sample, the specific surface area was found to be $\sim 145 \pm 7 \mathrm{~m}^{2} \mathrm{~g}^{-1}$, which is significantly greater than for the $\mathrm{NiMoO}_{4}$ system $\left(50 \pm 2 \mathrm{~m}^{2} \mathrm{~g}^{-1}\right)$. The Brunauer-Emmett-Teller (BET) plots of both samples are included in the supplementary material (see Figure S3). These results suggest that the flake structures of $\mathrm{NiWO}_{4}$ are highly porous even though they look more compact than the $\mathrm{NiMoO}_{4}$ structures.

\subsection{Electrochemical Characterization}

\subsubsection{Three-Electrode Configuration}

To evaluate the role of the molybdate $\left(\mathrm{MoO}_{4}{ }^{2-}\right)$ and tungstate $\left(\mathrm{WO}_{4}{ }^{2-}\right)$ anion on the electrochemical properties of Ni-based bimetallic oxides (BMOs), cyclic voltammetric studies (CV) and charge-discharge (CD) measurements were carried out in $2 \mathrm{M} \mathrm{NaOH}$ aqueous solution. The active material under investigation was coated on a graphite sheet substrate as a current collector. Graphite sheet is chosen as a suitable substrate because it is highly conductive. The redox peaks observed are solely attributed to $\mathrm{NiMoO}_{4}$ or $\mathrm{NiWO}_{4}$ active material. Hence, there is no capacitance contribution from the substrate itself. The CV curves of the blank graphite electrode as well as the $\mathrm{NiMoO}_{4}$ and $\mathrm{NiWO}_{4}$ 
coated electrode presented in the supplementary information section (Figure S4) clarifies this. Figure $9 \mathrm{~A}$ presents the $\mathrm{CV}$ curves of $\mathrm{NiMoO}_{4}$ at different scan rates. A pair of redox peaks (anodic $\mathrm{A}_{1}$, and cathodic $\mathrm{C}_{1}$ ) can be observed in a potential window of 0 to $0.6 \mathrm{~V}$ (vs. $\mathrm{Hg} / \mathrm{HgO}$ ) in all of the $\mathrm{CV}$ curves, implying that the redox behavior of the material is fully reversible and the charge storage in the $\mathrm{NiMoO}_{4}$ material is mainly governed by the electron transfer process, as given in Equation (5) [6]. The shape of the CV was retained at higher scan rates, illustrating the suitability of the material for high rate applications. The redox peak current increases linearly with an increasing sweep rate, suggesting a surface redox reaction, and the position of the redox peaks remains constant, which shows that the reaction mechanism is identical. The corresponding $\mathrm{CD}$ measurements at different current rates are presented in Figure 9B. The curves deviate from an ideal triangular-like shape, suggesting a characteristic pseudo-capacitive behavior. The mechanism involved in this reaction can be described as:

$$
\begin{gathered}
\mathrm{Ni}^{2+}\left(\mathrm{MoO}_{4}\right)^{2-}+\mathrm{OH}^{-} \leftrightarrow \mathrm{Ni}^{3+}\left(\mathrm{MoO}_{4}\right)^{2-}(\mathrm{OH})^{-}+\mathrm{e}^{-} \\
\mathrm{Mo}^{3+}+2 \mathrm{OH}^{-} \rightarrow \mathrm{Mo}(\mathrm{OH})_{2}^{+} \\
\mathrm{Mo}(\mathrm{OH})_{2}^{+}+\mathrm{OH}^{-} \rightarrow \mathrm{Mo}(\mathrm{OH})_{3} \\
\mathrm{Mo}(\mathrm{OH})_{3}+5 \mathrm{OH}^{-} \rightarrow \mathrm{MoO}_{4}^{2-}+4 \mathrm{H}_{2} \mathrm{O}+3 \mathrm{e}^{-}
\end{gathered}
$$



Figure 6. SEM images using a secondary electron (SE) detector at different magnifications: $(\mathbf{A}-\mathrm{C}) \mathrm{NiMoO}_{4},(\mathbf{D}-\mathbf{F}) \mathrm{NiWO}_{4}$ samples obtained by hydrothermal synthesis.
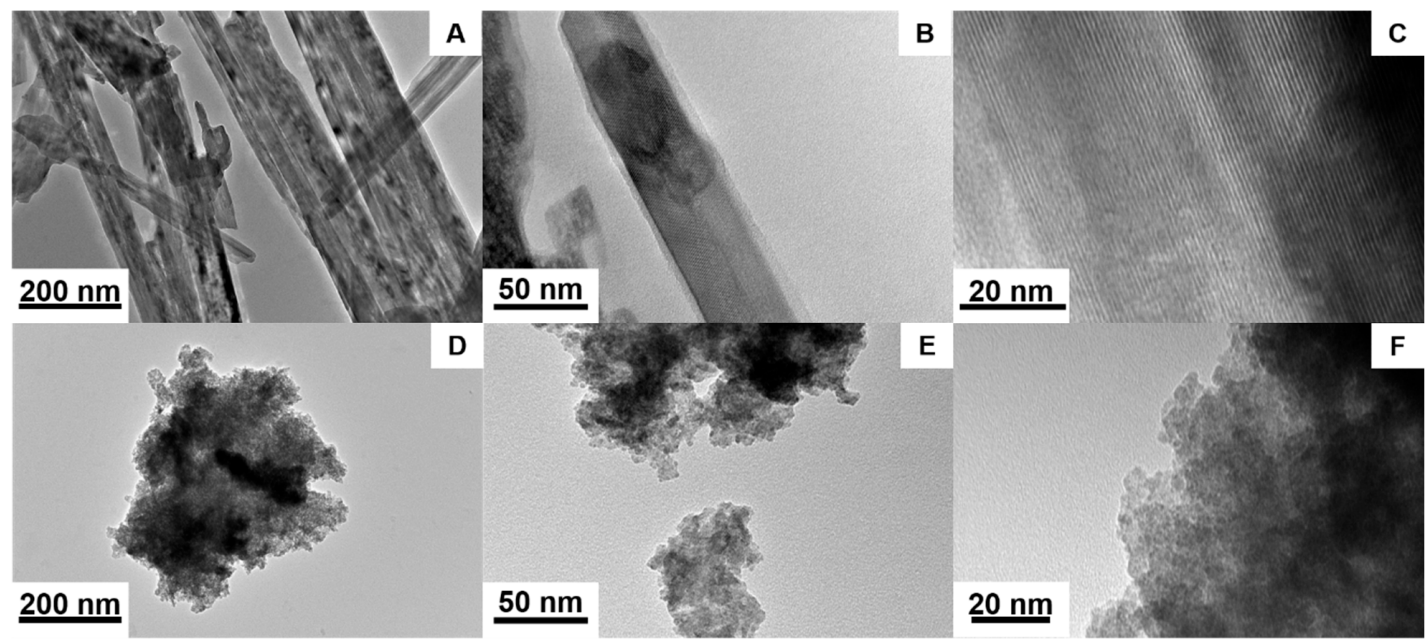

Figure 7. TEM images of the (A-C) $\mathrm{NiMoO}_{4}$ and (D-F) $\mathrm{NiWO}_{4}$ samples. 


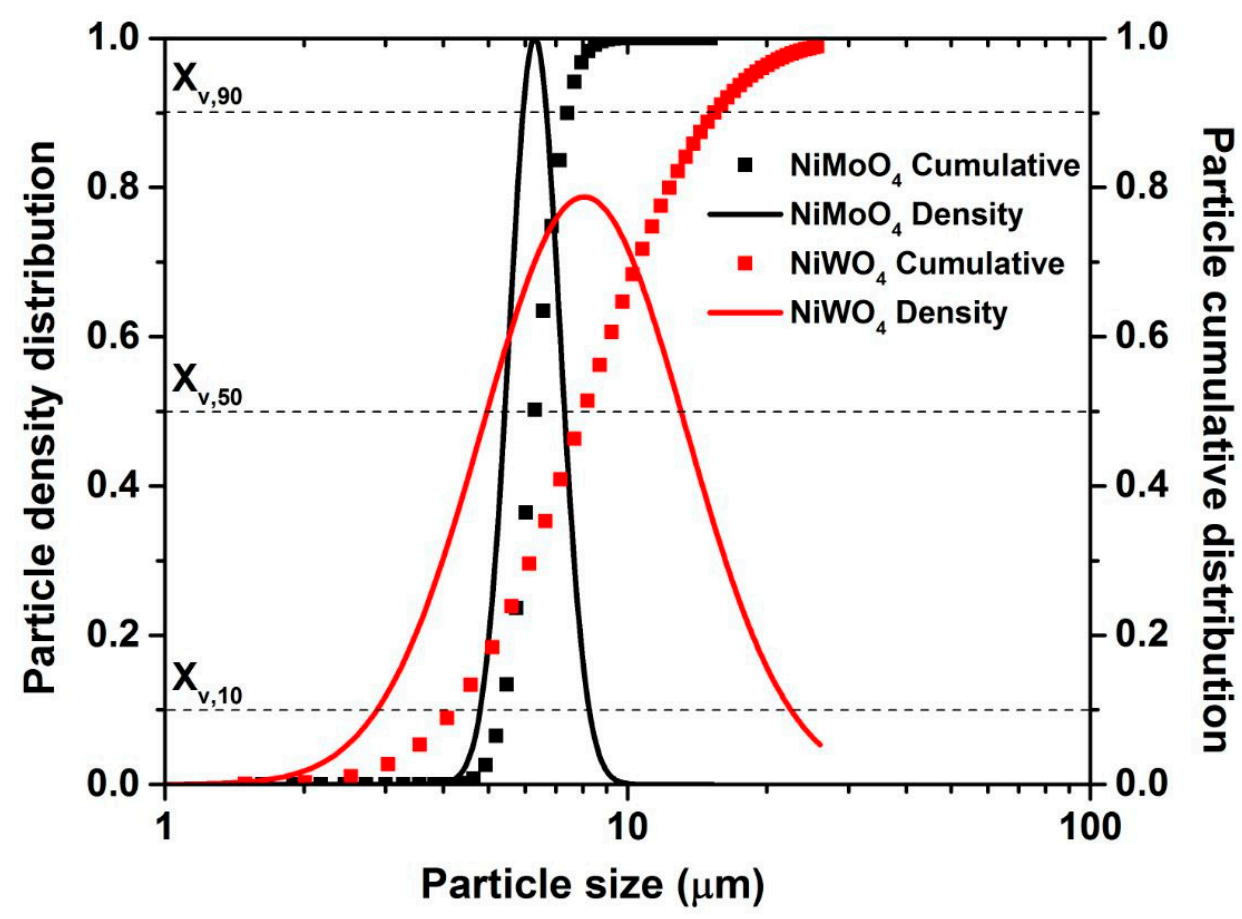

Figure 8. Cumulative (symbols) and density (solid lines) hydrodynamic particle size distribution obtained for $\mathrm{NiMoO}_{4}$ and $\mathrm{NiWO}_{4}$ after dispersion in $\mathrm{N}$-methyl-2-pyrrolidone (NMP).

Similarly, Figure 9C,D present the $\mathrm{CV}$ and the $\mathrm{CD}$ curves of $\mathrm{NiWO}_{4}$, respectively. In comparison to the curves observed for the Mo counterpart, the shape of the $\mathrm{CV}$ varies, having a lower current density. On the other hand, the redox peaks are better defined, indicating that an intercalation reaction may occur during the reduction and oxidation processes. As in $\mathrm{NiMoO}_{4}$, a pair of redox peaks $\left(\mathrm{A}_{1}\right.$ and $\left.\mathrm{C}_{1}\right)$ is observed at a potential window of 0 to $0.6 \mathrm{~V}$ (vs. $\mathrm{Hg} / \mathrm{HgO}$ ), showing evidence of the faradaic reaction between the $\mathrm{Ni}^{2+}$ and $\mathrm{Ni}^{3+}$ states, which is related to the diffusion of either $\mathrm{OH}^{-}$ions or $\mathrm{Na}^{+}$ions from the electrolyte [14]. On close inspection of the $\mathrm{CV}$ curves, a weak shoulder $\left(\mathrm{A}_{3}\right.$ and $\mathrm{C}_{3}$ ) is also seen, which can be attributed to the redox behavior of tungsten in alkaline solution. In addition, $\mathrm{CV}$ of pristine $\mathrm{WO}_{3}$ in a different potential window (Figure S5) was performed. This piece of experiment helps us to elucidate the association between the anodic and cathodic peak as the two oxidation peaks coincide and are difficult to differentiate. In an alkaline solution with the presence of an excess of $\mathrm{OH}^{-}$ions in the electrolyte, the molybdate reacts to $\mathrm{Mo}(\mathrm{OH})_{3}$ prior to any electrochemical processes, as shown in Equations (6)-(8), which is electrochemically inactive. The tungstate, however, is electrochemically active in an alkaline solution of $\mathrm{pH}>8$. The mechanism involved in the $\mathrm{NiWO}_{4}$ reaction in a solution with $\mathrm{pH}>8$ is shown in Equations (9)-(11) [32,33]. Equation (9) presents the overall mechanism taking place. Equation (10) demonstrates the reversible redox behavior of $\mathrm{Ni}$, whereas Equation (11) shows, in detail, the reaction of intermediate species formed during the process.

$$
\begin{gathered}
\mathrm{Ni}^{2+}\left(\mathrm{WO}_{4}\right)^{2-}+\mathrm{OH}^{-} \leftrightarrow \mathrm{Ni}^{3+}\left(\mathrm{WO}_{3}\right)^{2-}(\mathrm{OH})^{-}+\mathrm{e}^{-} \\
\mathrm{Ni}^{2+} \leftrightarrow \mathrm{Ni}^{3+}+\mathrm{e}^{-}(\text {peaks } \mathrm{A} 1 \text { and } \mathrm{C} 1) \\
\mathrm{WO}_{3}+\mathrm{OH}^{-} \rightarrow \mathrm{HWO}_{4}^{-} \leftrightarrow \mathrm{WO}_{4}^{2-}+\mathrm{H}^{+} \text {(peaks A2 and C2) }
\end{gathered}
$$



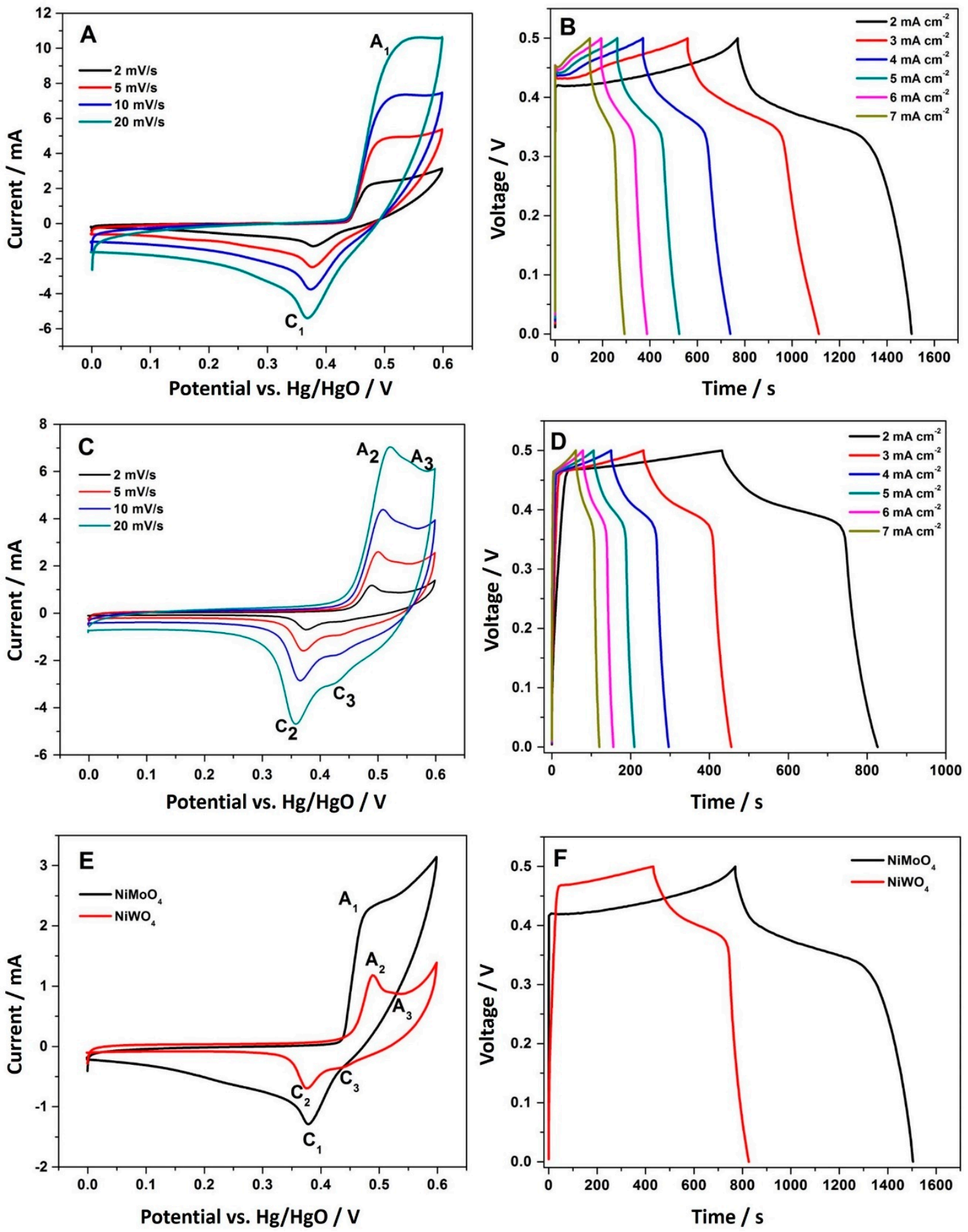

Figure 9. (A,B) Cyclic voltammetric (CV) curves and galvanostatic charge-discharge (CD) profiles of $\mathrm{NiMoO}_{4},(\mathbf{C}, \mathbf{D}) \mathrm{CV}$ curves and CD profiles of $\mathrm{NiWO}_{4},(\mathbf{E}, \mathbf{F})$ comparative $\mathrm{CV}$ at $2 \mathrm{mV} / \mathrm{s}$ and CD at $2 \mathrm{~mA} \mathrm{~cm}{ }^{-2}$ of $\mathrm{NiMoO}_{4}$ and $\mathrm{NiWO}_{4}$, respectively. The measurements are based on a three-electrode configuration with $\mathrm{Hg} / \mathrm{HgO}$ as the reference electrode.

Therefore, during the oxidation of $\mathrm{NiWO}_{4}, \mathrm{WO}_{3}$ forms in an anodic dissolution process. The degree of dissolution is directly proportional to the concentration of $\mathrm{OH}^{-}$ ions in the $\mathrm{NaOH}$ electrolyte solution [33]. This leads to the formation of a tungsten oxide layer on the surface, that passivates the electrode [32-35]. To confirm this mechanism, $\mathrm{WO}_{3}$ was synthesized and its electrochemical signature was verified. The $\mathrm{CV}$ curves for the pristine $\mathrm{WO}_{3}$ material (Figure S1B) exhibited an electrochemical activity at a similar potential to what is observed in Figure $9 \mathrm{C}$ for redox peaks $\mathrm{A}_{3}$ and $\mathrm{C}_{3}$, supporting the 
proposed mechanism. This behavior explains the inferior charge storage performance observed for the nickel tungstate compared to the nickel molybdate sample. In a typical case and under identical conditions, $\mathrm{NiMoO}_{4}$ took $1500 \mathrm{~s}$ to charge/discharge (Figure $9 \mathrm{~B}$ ), while the $\mathrm{NiWO}_{4}$ took half the amount of time (Figure 9D), resulting in a 50\% loss in charge storage. Similarly, the current response (area under the curve) of the $\mathrm{NiWO}_{4}$ has dropped significantly. Although it is widely believed that the role of the tungstate anion is to enhance the electrical conductivity and electrochemical properties, it is not observed here. The results in Figure $9 \mathrm{~F}$ show that the $\mathrm{NiMoO}_{4}$ electrode reflected its best specific capacitance at a current density of $2 \mathrm{~mA} \mathrm{~cm}^{-2}$. However, $\mathrm{NiWO}_{4}$ with its semi-crystalline form and the formation of the $\mathrm{WO}_{3}$ layer during the electrochemical reaction exhibited a poor specific capacitance at a current density of $2 \mathrm{~mA} \mathrm{~cm}^{-2}$. Therefore, the formation of $\mathrm{WO}_{3}$ affects the storage performance with the passivation layer further delaying the disproportionation of $\mathrm{NiWO}_{4}$.

\subsubsection{Two-Electrode Configuration}

To further ascertain the performance capability of a material that could be a suitable candidate for application in pseudo-capacitors, an asymmetric device consisting of $\mathrm{NiMoO}_{4}$ or $\mathrm{NiWO}_{4}$ as the cathode and activated carbon (AC) as the anode was constructed.

Figure $10 \mathrm{~A}, \mathrm{~B}$ demonstrate the $\mathrm{CV}$ curves recorded at a scan rate of $2 \mathrm{mV} \mathrm{s}^{-1}$ for $\mathrm{NiMoO}_{4}$ or $\mathrm{NiWO}_{4}, \mathrm{AC}$, and $\mathrm{Hg} / \mathrm{HgO}$ as the reference electrode in a three-electrode configuration. It can be inferred that $\mathrm{NiMoO}_{4}$ and $\mathrm{NiWO}_{4}$ are both suitable cathode materials, being active in the positive potential region $(0$ to $0.6 \mathrm{~V}) \mathrm{vs}$. $\mathrm{Hg} / \mathrm{HgO}$ with activated carbon acting as the anode in the negative potential region $(0$ to $-1 \mathrm{~V})$. By coupling the electrodes together, the total potential window in a two-electrode system is, hence, determined as 1.6 V. As seen in the CV curves (see Figure 10A,B), AC shows a quasirectangular shape, which indicates an electric double layer mechanism for charge storage. In contrast, $\mathrm{NiMoO}_{4}$ and $\mathrm{NiWO}_{4}$ demonstrate a pair of clear redox peaks, indicative of the pseudo-capacitive nature of the material.
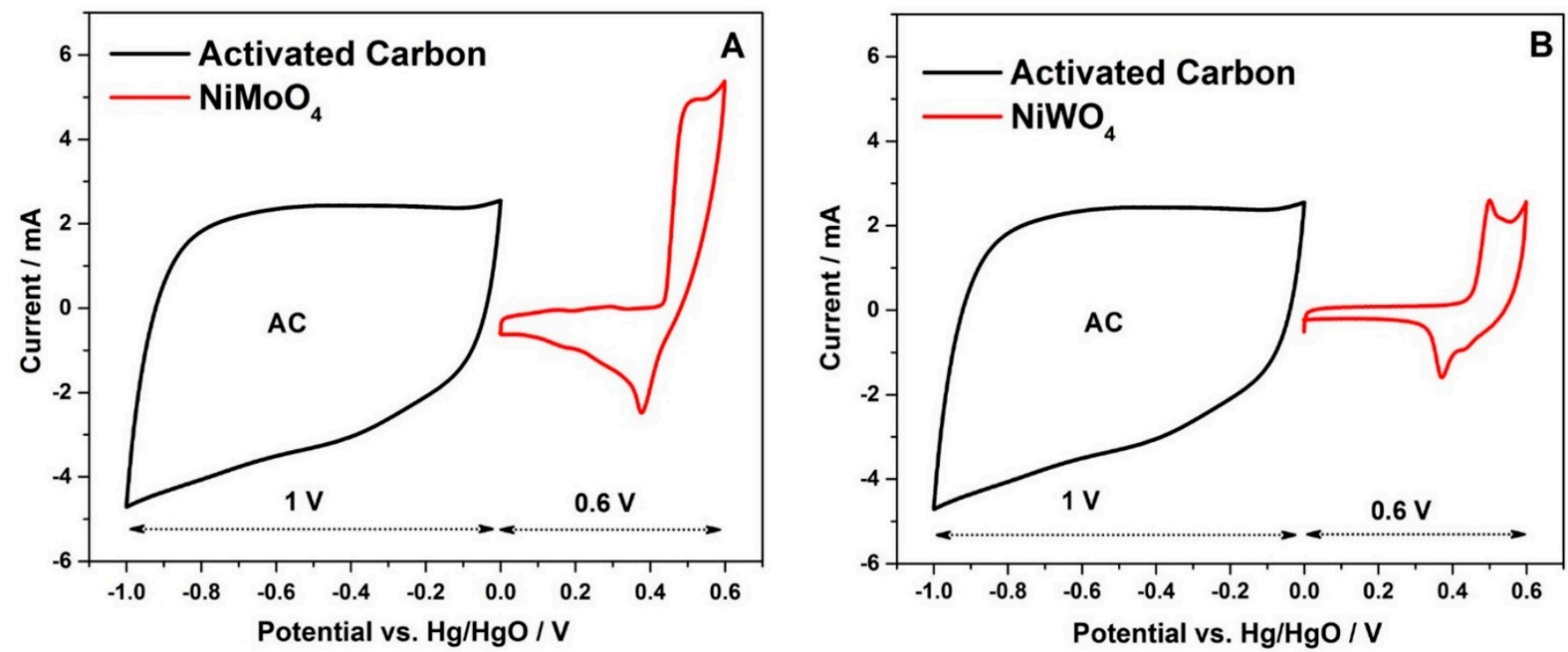

Figure 10. (A,B) Cyclic voltammetric curves of $\mathrm{NiMoO}_{4}$ and $\mathrm{NiWO}_{4}$ along with activated carbon (AC) recorded in a three-electrode configuration with $\mathrm{Hg} / \mathrm{HgO}$ as the reference electrode.

Figure 11 shows a comparative $\mathrm{CV}$ and $\mathrm{CD}$ of $\mathrm{NiMoO}_{4}$ and $\mathrm{NiWO}_{4}$ vs. $\mathrm{AC}$ in the asymmetric cell. The area enclosed within the $\mathrm{CV}$ curve of $\mathrm{NiMoO}_{4}$ is slightly enhanced compared to that of $\mathrm{NiWO}_{4}$ (Figure 11A), implying that $\mathrm{NiMoO}_{4}$ delivers greater specific capacitance. 

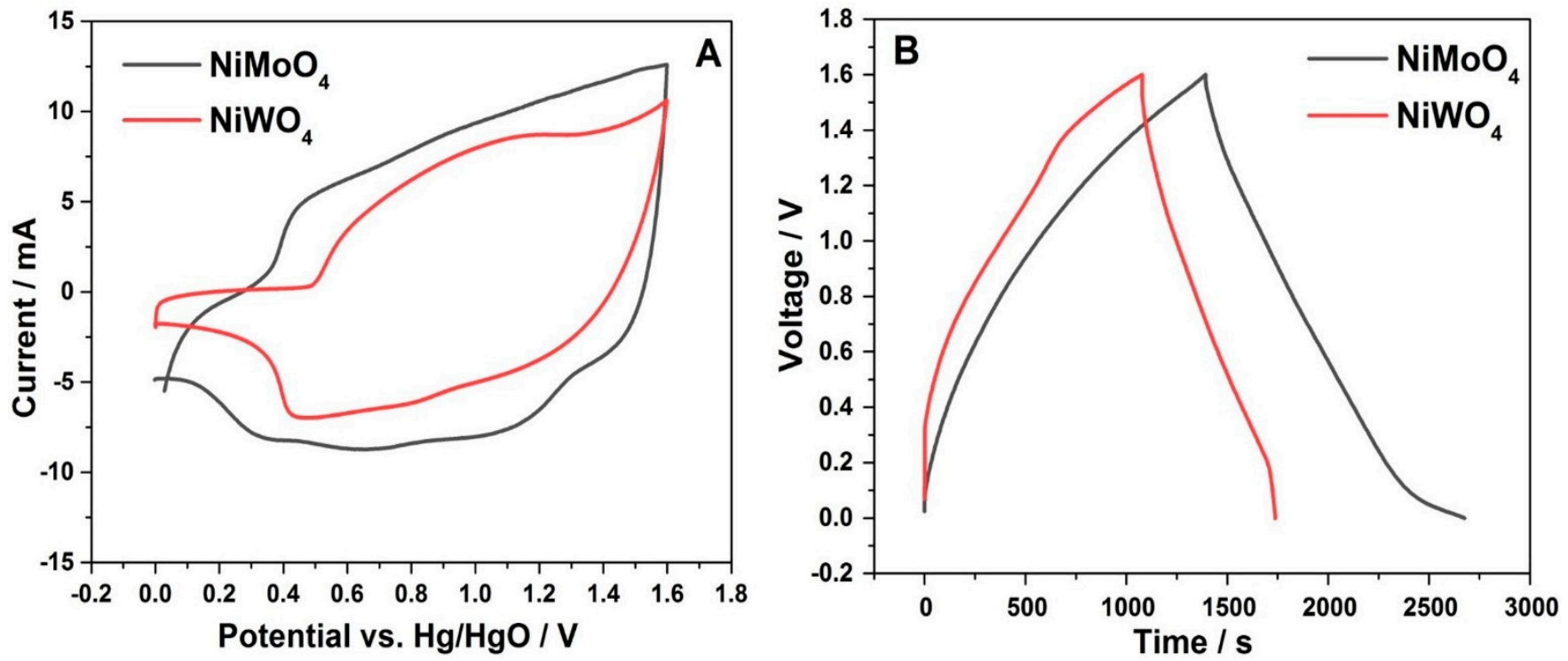

Figure 11. Comparative (A) cyclic voltammetric curves at $5 \mathrm{mV} \mathrm{s}^{-1}$, and (B) charge-discharge profiles at $3 \mathrm{~mA} \mathrm{~cm}^{-2}$ of $\mathrm{NiMoO}_{4}$ and $\mathrm{NiWO}_{4}$ asymmetric devices, respectively, in $2 \mathrm{M} \mathrm{NaOH}$ solution.

This result is further supported by the corresponding charge-discharge profiles (Figure 11B), where the discharge time for the $\mathrm{NiMoO}_{4}$ material is longer by about $1000 \mathrm{~s}$ for an equal mass of the active material in both systems.

A detailed electrochemical investigation of $\mathrm{NiMoO}_{4}$ and $\mathrm{NiWO}_{4}$ is shown in Figure 12. Using Equation (1), the specific capacitance at an applied current of $3 \mathrm{~mA} \mathrm{~cm}^{-2}$ was found to be 134 and $83 \mathrm{~F} \cdot \mathrm{g}^{-1}$ for $\mathrm{NiMoO}_{4}$ and $\mathrm{NiWO}_{4}$, respectively. Both materials were able to retain a high specific capacitance of $82.87 \mathrm{~F} \cdot \mathrm{g}^{-1}\left(\mathrm{NiMoO}_{4}\right)$ and $74.37 \mathrm{~F} \cdot \mathrm{g}^{-1}\left(\mathrm{NiWO}_{4}\right)$ even at a higher applied current of $7 \mathrm{~mA} \mathrm{~cm}^{-2}$. Using Equations (2) and (3), the energy and power density at $3 \mathrm{~mA} \mathrm{~cm}{ }^{-2}$ applied current were calculated to be $47.52 \mathrm{~W} \mathrm{~h} \mathrm{~kg}^{-1}$ and $481.11 \mathrm{~W} \mathrm{~kg}^{-1}$ for $\mathrm{NiMoO}_{4}$, and $29.4 \mathrm{~W} \mathrm{~h} \mathrm{~kg}{ }^{-1}$ and $575.56 \mathrm{~W} \mathrm{~kg}^{-1}$ for $\mathrm{NiWO}_{4}$, respectively. A combination of redox and electric double layer capacitator (EDLC) behavior was observed in the CV curves (Figure 12A,D), which illustrates the pseudocapacitive nature of $\mathrm{NiMoO}_{4}$ and $\mathrm{NiWO}_{4}$ and the electric double layer property of $\mathrm{AC}$.

To obtain further insights on the charge transport behavior of both materials, electrochemical impedance spectroscopy (EIS) was performed (Figure 13A). The fitted equivalent circuit for both Nyquist plots is shown in the inset. Each plot shows two distinct regions: a semi-circle in the high-frequency area corresponds to $\mathrm{R}_{\mathrm{ct}}$ (charge transfer resistance) and $R_{S}$ (solution resistance) of the hybrid cell, followed by a linear region in the low-frequency area, which relates to chemical diffusion impedance, termed as Warburg impedance (W). It is noted that the diameter of the semicircle arc in the high frequency region is larger for $\mathrm{NiWO}_{4}$. This represents the difference in electrochemical charge transport between $\mathrm{NiMoO}_{4}$ and $\mathrm{NiWO}_{4}$, with a supercapacitor-type and hybrid-type behavior, respectively. The values of $R_{c t}, R_{s}$, and $W$ for $\mathrm{NiMoO}_{4}$ vs. AC were calculated to be $0.019 \Omega \mathrm{cm}^{2}$, $1.04 \Omega \mathrm{cm}^{2}$, and $3.175 \Omega \mathrm{cm}^{2} \mathrm{~s}^{-1 / 2}$. In the case of $\mathrm{NiWO}_{4} \mathrm{vs}$. AC, the values were found to be $0.284 \Omega \mathrm{cm}^{2}, 3.712 \Omega \mathrm{cm}^{2}$, and $1.466 \Omega \mathrm{cm}^{2} \mathrm{~s}^{-1 / 2}$ for $R_{\mathrm{ct}}, R_{\mathrm{s}}$, and $\mathrm{W}$, respectively. The steep slope of the Warburg line for $\mathrm{NiMoO}_{4}$ relates to the good diffusion capability of ions in the system. Furthermore, the surface film resistance values $\left(\mathrm{R}_{\mathrm{f}}\right)$ for $\mathrm{NiMoO}_{4}$ vs. AC and $\mathrm{NiWO}_{4}$ vs. AC were found to be $18.7 \Omega \mathrm{cm}^{2}$ and $32.8 \Omega \mathrm{cm}^{2}$, respectively, which corresponds to a solid electrolyte interface (SEI) layer formation. An additional constant phase element (CPE), denoted as $Q$ in the circuit, represents the non-ideal capacitive behavior of the electrode material. This parameter originates from redox mechanisms being involved during the energy storage process. The fitted results showed CPE values of $1.42 \times 10^{-3} \Omega^{-1} \mathrm{~cm}^{2}$ s and $2.35 \times 10^{-3} \Omega^{-1} \mathrm{~cm}^{2} \mathrm{~s}$ for the $\mathrm{NiMoO}_{4} \mathrm{vs}$. AC device, while $3.28 \times 10^{-3} \Omega^{-1} \mathrm{~cm}^{2} \mathrm{~s}$ and $4.12 \times 10^{-3} \Omega^{-1} \mathrm{~cm}^{2} \mathrm{~s}$ were obtained for $\mathrm{NiWO}_{4} \mathrm{vs}$. AC. This 
data supports the overall superior electrochemical performance of the $\mathrm{NiMoO}_{4}$ electrode. Arguably, if the tungstate anion were beneficial for enhancing the electrical conductivity, the observed impedance values should be lower than for the molybdate. Therefore, the role of the anodic dissolution of $\mathrm{WO}_{3}$ plays a dominant role, determining the electrochemical performance rather than the conductivity. The result shows that the electrolyte ions and electrons show higher transfer rates in $\mathrm{NiMoO}_{4}$.
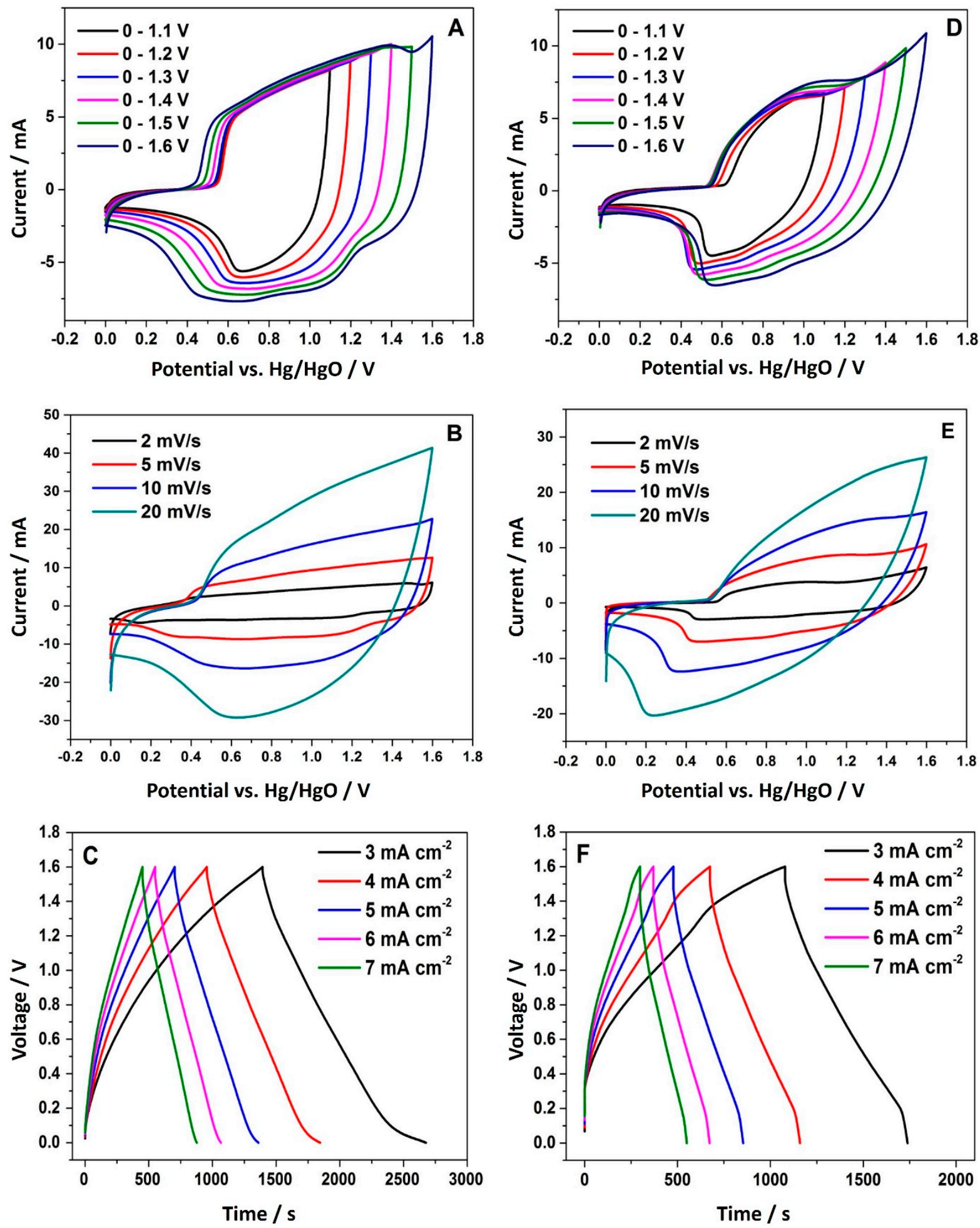

Figure 12. Electrochemical measurements of asymmetric cells: Cyclic voltammetric (CV) curves of $\mathrm{NiMoO}_{4}(\mathbf{A})$ and $\mathrm{NiWO}_{4}$ (D) at different potential windows at a scan rate of $5 \mathrm{mV} \mathrm{s}^{-1}, \mathrm{CV}$ curves of $\mathrm{NiMoO}_{4}(\mathbf{B})$, and $\mathrm{NiWO}_{4}($ E) at different scan rates and galvanostatic charge-discharge (CD) profile of $\mathrm{NiMoO}_{4}(\mathbf{C})$ and $\mathrm{NiWO}_{4}(\mathbf{F})$ at different applied currents. 

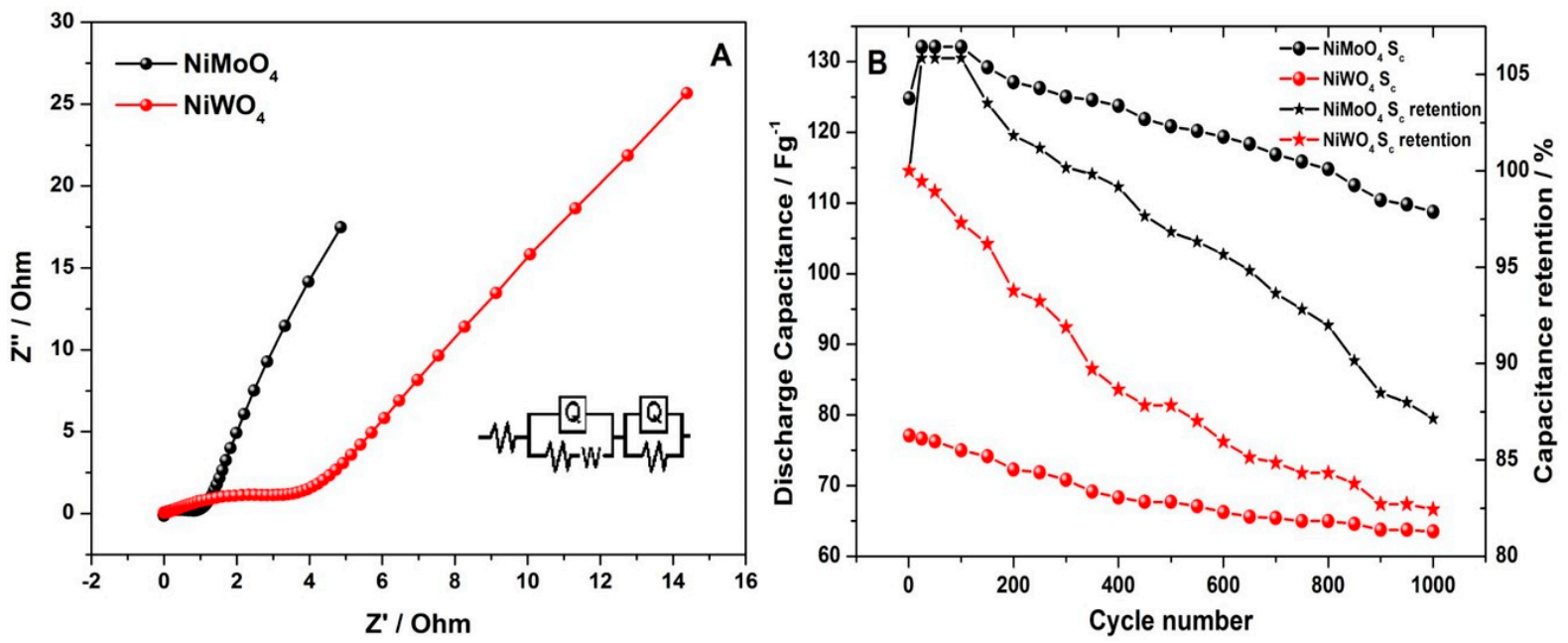

Figure 13. (A) Electrochemical impedance spectroscopy (EIS) results of $\mathrm{NiMoO}_{4}$ and $\mathrm{NiWO}_{4}$ hybrid cells presented as a comparative Nyquist plot and (B) cycle stability at an applied current density of $5 \mathrm{~mA} \mathrm{~cm}^{-2}$ demonstrating the device capacitance and its retention percentage.

For the practicality in applications, electrochemical stability is an important factor to be considered for pseudo-capacitors and it is presented in Figure 13B. The chargedischarge measurements were performed within a voltage window of $1.6 \mathrm{~V}$ at a current density of $5 \mathrm{~mA} \mathrm{~cm}^{-2}$ for 1000 continuous cycles. It is observed that, at the end of the investigation, the asymmetric devices, $\mathrm{NiMoO}_{4}$ vs. $\mathrm{AC}$ and $\mathrm{NiWO}_{4}$ vs. $\mathrm{AC}$ retained $87.14 \%$ and $82.44 \%$ of their initial capacitance, respectively. The relative difference in capacity loss between the two materials is marginal. However, their initial storage capacitance values are significantly different. This is attributed to the role of the anions in the binary metal oxide electrodes. Thus, $\mathrm{NiMoO}_{4}$ is highly promising as potential electrode material, while the anodic dissolution of $\mathrm{WO}_{3}$ in alkaline solution passivates the $\mathrm{NiWO}_{4}$ electrode, which is reducing its storage capacitance.

\section{Conclusions}

$\mathrm{NiMoO}_{4}$ and $\mathrm{NiWO}_{4}$ as two Ni-based BMOs were synthesized via a hydrothermal method and electrochemically tested as hybrid electrodes for pseudo-capacitors. The characterization of the samples via XRD, XPS, and Raman corroborates that both synthesized materials are a combination of $\mathrm{Ni}-\mathrm{Mo}$ and $\mathrm{Ni}-\mathrm{W}$ in the predicted atomic ratio forming a monoclinic crystal structure. The morphology and specific surface area of the prepared materials were significantly different, with $\mathrm{NiWO}_{4}$ exhibiting a high specific surface area, which is usually considered advantageous to increasing the specific capacitance. However, $\mathrm{NiMoO}_{4}$ delivers better electrochemical properties, suggesting that the redox reaction mechanism has a higher influence than the morphology. The redox reaction for $\mathrm{NiMoO}_{4}$ only involves the faradaic reaction between $\mathrm{Ni}^{2+}$ and $\mathrm{Ni}^{3+}$ at the surface, allowing high capacity and longer charge storage performance. $\mathrm{NiWO}_{4}$ shows a two-step redox reaction with, on one hand, the contribution from $\mathrm{Ni}$ and, on the other hand, the participation of a tungsten oxide layer. The latter is the result of a reaction of tungstate with the electrolyte, forming $\mathrm{WO}_{3}$, which is deposited at the surface of the electrode, forming a passivation layer that decreases the capacitance. As the main conclusion, $\mathrm{NiMoO}_{4}$ should be considered as the favorite candidate for pseudo-capacitor applications. The anion of the compound, hence, can play a decisive role in BMOs for electrochemical applications and lead to substantial changes in the charge storage mechanism. 
Supplementary Materials: The following are available online at https: / /www.mdpi.com/2079-4 991/11/3/580/s1. S1. Hydrothermal synthesis of tungsten oxide $\left(\mathrm{WO}_{3}\right)$. Figure S1: (A) X-ray diffraction (XRD) pattern of hydrothermally synthesized $\mathrm{WO}_{3}$ and (B) cyclic voltammetric $(\mathrm{CV})$ curves of $\mathrm{WO}_{3}$ with different scan rates in $2 \mathrm{M} \mathrm{NaOH}$ solution based on three-electrode configuration with $\mathrm{Hg} / \mathrm{HgO}$ as the reference electrode. Figure S2: XPS survey spectra of $\mathrm{NiMoO}_{4}$ (black color) and $\mathrm{NiWO}_{4}$ (red color). Figure S3: BET plot of $\mathrm{NiMoO}_{4}$ and $\mathrm{NiWO}_{4}$ using points collected at the pressure range between 0.1 to 0.3 . Figure S4: A comparative cyclic voltammetric (CV) curves of a blank graphite sheet. $\mathrm{NiMoO}_{4}$-coated and $\mathrm{NiWO}_{4}$-coated graphite sheet to demonstrate no capacitance contribution is coming from the graphite substrate. The experiment is carried out in three-electrode configurations with $\mathrm{Hg} / \mathrm{HgO}$ as the reference electrode at $2 \mathrm{mV} / \mathrm{s}$ scan rate in $2 \mathrm{M} \mathrm{NaOH}$ solution. Figure S5: Cyclic voltammetric (CV) curves of $\mathrm{WO}_{3}$ at $5 \mathrm{mV} / \mathrm{s}$ in $2 \mathrm{M} \mathrm{NaOH}$ solution based on three-electrode configuration with $\mathrm{Hg} / \mathrm{HgO}$ as the reference electrode with a different potential window. This experiment helps us to elucidate the association between an anodic and cathodic peak as the two oxidation peaks coincide and are difficult to differentiate.

Author Contributions: Methodology, G.G. and M.M. Formal analysis and investigation, A.J.-F. and P.S. Writing-original draft preparation, A.J.-F. and P.S. Writing-review and editing, G.G., M.M. and J.W. Supervision and project administration, G.G. and M.M. Funding acquisition, G.G. and M.M. All authors have read and agreed to the published version of the manuscript.

Funding: This work was supported by the DAAD-PPP program (grant number 57520587) as well as the Ministry of Science and Culture of Lower Saxony within the "Forschungslinie MOBILISE". Moreover, we acknowledge support by the German Research Foundation and the Open Access Publication Funds of Technische Universität Braunschweig.

Data Availability Statement: The data presented in this study are available within this article. Further inquiries may be directed to the authors.

Acknowledgments: We thank Bilal Temel, Institute for Particle Technology, and the Laboratory for Nano and Quantum Engineering (LNQE), Leibniz University Hannover, for the TEM measurements.

Conflicts of Interest: The authors declare no conflict of interest.

\section{References}

1. Miller, E.E.; Hua, Y.; Tezel, F.H. Materials for energy storage: Review of electrode materials and methods of increasing capacitance for supercapacitors. J. Energy Storage 2018, 20, 30-40. [CrossRef]

2. An, C.; Zhang, Y.; Guo, H.; Wang, Y. Metal oxide-based supercapacitors: Progress and prospectives. Nanoscale Adv. 2019, 1, 4644-4658. [CrossRef]

3. Minakshi, M.; Mitchell, D.R.G.; Jones, R.T.; Pramanik, N.C.; Jean-Fulcrand, A.; Garnweitner, G. A Hybrid Electrochemical Energy Storage Device Using Sustainable Electrode Materials. ChemistrySelect 2020, 5, 1597-1606. [CrossRef]

4. Wang, G.; Zhang, L.; Zhang, J. A review of electrode materials for electrochemical supercapacitors. Chem. Soc. Rev. 2012, 41,797-828. [CrossRef] [PubMed]

5. Zhang, G.; Lou, X.W.D. General solution growth of mesoporous $\mathrm{NiCo}_{2} \mathrm{O}_{4}$ nanosheets on various conductive substrates as high-performance electrodes for supercapacitors. Adv. Mater. 2013, 25, 976-979. [CrossRef]

6. Cai, D.; Wang, D.; Liu, B.; Wang, Y.; Liu, Y.; Wang, L.; Li, H.; Huang, H.; Li, Q.; Wang, T. Comparison of the electrochemical performance of $\mathrm{NiMoO}_{4}$ nanorods and hierarchical nanospheres for supercapacitor applications. ACS Appl. Mater. Interfaces 2013, 5, 12905-12910. [CrossRef]

7. Tang, X.; Zhang, B.; Lui, Y.H.; Hu, S. Ni-Mn bimetallic oxide nanosheets as high-performance electrode materials for asymmetric supercapacitors. J. Energy Storage 2019, 25, 100897. [CrossRef]

8. De Oliveira, A.L.M.; Ferreira, J.M.; Silva, M.R.S.; de Souza, S.C.; Vieira, F.T.G.; Longo, E.; Souza, A.G.; Santos, I.M.G. Influence of the thermal treatment in the crystallization of $\mathrm{NiWO}_{4}$ and $\mathrm{ZnWO}_{4}$. J. Therm. Anal. Calorim. 2009, 97, 167-172. [CrossRef]

9. Baoyi, S.; Aiju, X.; Jiang, W. The impact of preparation methods on the structure and catalytic performance of $\mathrm{NiMoO}_{4}$ for oxidative dehydrogenation of propane. Integr. Ferroelectr. 2016, 171, 16-22. [CrossRef]

10. Klissurski, D.; Mancheva, M.; Iordanova, R.; Tyuliev, G.; Kunev, B. Mechanochemical synthesis of nanocrystalline nickel molybdates. J. Alloys Compd. 2006, 422, 53-57. [CrossRef]

11. AlShehri, S.M.; Ahmed, J.; Alzahrani, A.M.; Ahamad, T. Synthesis, characterization, and enhanced photocatalytic properties of $\mathrm{NiWO}_{4}$ nanobricks. New J. Chem. 2017, 41, 8178-8186. [CrossRef]

12. Wang, B.; Li, S.; Wu, X.; Tian, W.; Liu, J.; Yu, M. Integration of network-like porous $\mathrm{NiMoO}_{4}$ nanoarchitectures assembled with ultrathin mesoporous nanosheets on three-dimensional graphene foam for highly reversible lithium storage. J. Mater. Chem. A 2015, 3, 13691-13698. [CrossRef] 
13. Moreno, B.; Chinarro, E.; Colomer, M.T.; Jurado, J.R. Combustion Synthesis and Electrical Behavior of Nanometric $\beta-N_{i M o O}$. J. Phys. Chem. C 2010, 114, 4251-4257. [CrossRef]

14. Niu, L.; Li, Z.; Xu, Y.; Sun, J.; Hong, W.; Liu, X.; Wang, J.; Yang, S. Simple synthesis of amorphous $\mathrm{NiWO}_{4}$ nanostructure and its application as a novel cathode material for asymmetric supercapacitors. ACS Appl. Mater. Interfaces 2013, 5, 8044-8052. [CrossRef]

15. Chen, S.; Yang, G.; Jia, Y.; Zheng, H. Three-dimensional $\mathrm{NiCo}_{2} \mathrm{O}_{4} @ \mathrm{NiWO}_{4}$ core-shell nanowire arrays for high performance supercapacitors. J. Mater. Chem. A 2017, 5, 1028-1034. [CrossRef]

16. Garnweitner, G.; Xue, D. Crystal engineering for electrochemical applications. CrystEngComm 2020, 22, 1498-1499. [CrossRef]

17. Chen, Y.-Y.; Zhang, Y.; Zhang, X.; Tang, T.; Luo, H.; Niu, S.; Dai, Z.-H.; Wan, L.-J.; Hu, J.-S. Self-Templated Fabrication of MoNi4 /MoO3-x Nanorod Arrays with Dual Active Components for Highly Efficient Hydrogen Evolution. Adv. Mater. $2017,29,1703311$. [CrossRef]

18. Dury, F.; Gaigneaux, E.M.; Ruiz, P. The active role of $\mathrm{CO} 2$ at low temperature in oxidation processes: The case of the oxidative dehydrogenation of propane on NiMoO4 catalysts. Appl. Catal. A 2003, 242, 187-203. [CrossRef]

19. De Moura, A.P.; de Oliveira, L.H.; Rosa, I.L.V.; Xavier, C.S.; Lisboa-Filho, P.N.; Li, M.S.; La Porta, F.A.; Longo, E.; Varela, J.A. Structural, optical, and magnetic properties of $\mathrm{NiMoO}_{4}$ nanorods prepared by microwave sintering. Sci. World J. 2015, $2015,315084$. [CrossRef]

20. Abdel-Dayem, H.M. Dynamic Phenomena during Reduction of $\alpha-\mathrm{NiMoO}_{4}$ in Different Atmospheres: In-Situ Thermo-Raman Spectroscopy Study. Ind. Eng. Chem. Res. 2007, 46, 2466-2472. [CrossRef]

21. Zou, J.Y.; Schrader, G.L. Deposition of multiphase molybdate thin films by reactive sputtering. Thin Solid Films 1997, 324, 52-62. [CrossRef]

22. Hanuza, J.; Maczka, M.; Van der Maas, J.H. Vibrational Properties of Double Tungstates of the MIMIII(WO4)2 Family (MI = Li, $\mathrm{Na}, \mathrm{K} ; \mathrm{MIII}=\mathrm{Bi}, \mathrm{Cr})$. J. Solid State Chem. 1995, 117, 177-188. [CrossRef]

23. Ross-Medgaarden, E.I.; Wachs, I.E. Structural Determination of Bulk and Surface Tungsten Oxides with UV-vis Diffuse Reflectance Spectroscopy and Raman Spectroscopy. J. Phys. Chem. C 2007, 111, 15089-15099. [CrossRef]

24. Zawawi, S.M.; Yahya, R.; Hassan, A.; Ekramul Mahmud, H.N.M.; Daud, M.N. Structural and optical characterization of metal tungstates (MWO4; M=Ni, Ba, Bi) synthesized by a sucrose-templated method. Chem. Cent. J. 2013, 7, 80. [CrossRef] [PubMed]

25. Doudin, N.; Pomp, S.; Blatnik, M.; Resel, R.; Vorokhta, M.; Goniakowski, J.; Noguera, C.; Netzer, F.P.; Surnev, S. Epitaxial NiWO4 films on $\mathrm{Ni}(110)$ : Experimental and theoretical study of surface stability. Surface Sci. 2017, 659, 20-30. [CrossRef]

26. Vroulias, D.; Gkoulemani, N.; Papadopoulou, C.; Matralis, H. W-modified Ni/ $\mathrm{Al}_{2} \mathrm{O}_{3}$ catalysts for the dry reforming of methane: Effect of W loading. Catal. Today 2019, 355, 704-715. [CrossRef]

27. Lima, N.A.; Alencar, L.D.S.; Siu-Li, M.; Feitosa, C.A.C.; Mesquita, A.; M'peko, J.-C.; Bernardi, M.I.B. NiWO4 powders prepared via polymeric precursor method for application as ceramic luminescent pigments. J. Adv. Ceram. 2020, 9, 55-63. [CrossRef]

28. Harshan, H.; Priyanka, K.P.; Sreedevi, A.; Jose, A.; Varghese, T. Structural, optical and magnetic properties of nanophase NiWO4 for potential applications. Eur. Phys. J. B 2018, 91, 10356. [CrossRef]

29. Anspoks, A.; Kalinko, A.; Timoshenko, J.; Kuzmin, A. Local structure relaxation in nanosized tungstates. Solid State Commun. 2014, 183, 22-26. [CrossRef]

30. Sharma, P.; Minakshi Sundaram, M.; Watcharatharapong, T.; Laird, D.; Euchner, H.; Ahuja, R. Zn Metal Atom Doping on the Surface Plane of One-Dimesional NiMoO4 Nanorods with Improved Redox Chemistry. ACS Appl. Mater. Interfaces 2020, 12, 44815-44829. [CrossRef]

31. Green, S.V.; Kuzmin, A.; Purans, J.; Granqvist, C.G.; Niklasson, G.A. Structure and composition of sputter-deposited nickeltungsten oxide films. Thin Solid Films 2011, 519, 2062-2066. [CrossRef]

32. Heumann, T.H.; Stolica, N. The electrochemical behaviour of tungsten-II. The dissolution of tungsten in $\mathrm{NaOH}$ solutions. Electrochim. Acta 1971, 16, 1635-1646. [CrossRef]

33. Tuvić, T.; Pašti, I.; Mentus, S. Tungsten electrochemistry in alkaline solutions-Anodic dissolution and oxygen reduction reaction. Russ. J. Phys. Chem. 2011, 85, 2399-2405. [CrossRef]

34. Ortiz, P.I.; Giordano, M.C.; Lopez Teijelo, M. Electrochemical behaviour of tungsten in alkaline media Part II. Sodium carbonate solutions. J. Electroanal. Chem. Interfacial Electrochem. 1988, 251, 393-401. [CrossRef]

35. Krtil, P.; Fattakhova, D.; Yoshimura, M. Mechanism of soft solution processing formation of alkaline earth metal tungstates: An electrochemical and in situ AFM study. J. Solid State Electrochem. 2002, 6, 367-373. [CrossRef] 